\title{
Influence of Open-End Funds on Stock Market Volatility-Analysis Based on Shanghai Composite
}

\author{
Na Zhu \\ College of Economics, Jinan University, Guangzhou, China \\ Email: 318623602@qq.com
}

Received 15 February 2016; accepted 18 April 2016; published 22 April 2016

Copyright (C) 2016 by author and Scientific Research Publishing Inc.

This work is licensed under the Creative Commons Attribution International License (CC BY). http://creativecommons.org/licenses/by/4.0/

\begin{abstract}
This article establishes the econometric model, selects stock data of Shanghai composite index from January 2, 1997 to December 31, 2012 as the basis of research. The whole period can be divided into two small periods with the time when open-ended fund enters into stock market as the boundary. Then, this article divides each small period into bear market period and bull market period and analyzes the different influences of open-ended fund on volatility of yield rate of Chinese stock market in different period. Firstly, this article adopts GARCH-M model, which can consider investment risk factors in mean equation. According to test of GARCH-M model, leverage effect can be seen in stock market volatility so that asymmetric EGARCH-M model which can also consider investment risk is introduced to capture the asymmetric influence posed by positive and negative impact.
\end{abstract}

\section{Keywords}

Open-End, Stock Market Volatility, GARCH-M Model, EGARCH-M Model

\section{Introduction}

Chinese stock market, as trial in 1989, has been developed for only 20 years. It still has been in the course of development and improvement. Obvious policy effects exist in the course of development. That means government policies would have direct intervention on stock market, and pose influence on the stock price. Meanwhile, Chinese stock market mechanisms and all laws and regulations haven't leveraged their full potential yet. Individual investor is still the main form of structure of investors, which is also the main reason of Chinese stock market fluctuation.

After summarizing international and domestic theory and empirical study, we can find that most scholars at- 
tach importance to the relationship between open-ended fund and stock market fluctuation from the aspect of investment behavior instead of different conclusions caused by different market conditions and market environments. Currently, international and domestic scholars summarize the influence of open-ended fund on stock market volatility from the view of market environment.

Warther (1998) found that as investors may compare all open-ended funds earnings in the market, then decide their further purchases [1]. If investors find the fund which they invest in has lower earnings, they will choose to redempt or purchase other funds, which add to the fund market pressure, so the funds may follow those combinations with higher earnings, thereby exacerbating the volatility of the stock market.

Daniel and Subramanyam (1998) find that investors intend to take the positive feedback trading due to common psychology [2]. When there is a good thing, investors may think it's their ability that makes it happen, but for emergence of some bad things they often attribute to their bad luck or the external environment. When the prices of the shares they hold rise, they will show more confidence because the market runs in line with their own expectations, which also leads to the positive feedback trading, increasing the stock price volatility

Chang and Ying Wang (2002) think that funds will make the asymmetric responses to different market environments [3]. When the market is in decline, individual investors increase redemption of fund, and fund managers have to sell more stocks from its portfolio in order to meet their liquidity needs. In addition, when the stock market falls, fund managers tend to be panic and overreact to market information. So, for fund managers, selling stocks contained less information than buying stocks. This disproportionate response will lead to more severe market decline, and further aggravate stock market volatility. Their empirical results verify that stock market volatility and fund flows have negative synchronous correlation, and that fund inflows and stock market volatility have obvious asymmetric effects, which can be seen in the negative correlation between fund outflows and market volatility and in the positive correlation between fund outflows and market volatility.

Chiyachantana, Jain, Jiang and Wood (2004) find that, in the bull market during 1997-1998, buying transaction has more influence than selling transaction. In the bear market from January, 2001 to September, 2001, the selling transaction of institutional investors causes bigger fluctuation to share price than buying transaction [4]. They can find asymmetric phenomenon through different countries and different months. Because buyers, as the consumer of market volatility, are in a leading position. But sellers are the supplier of market volatility. To buy stocks, buyers must pay high liquidity premium to sellers if buyers could get stocks. Therefore, transaction of buyers could lead to bigger fluctuation of stock price in bull market. It couldn't be in bear market.

Empirical study of He Jia and He Jibao shows that institutional investors have relatively small influence on the whole market price. While, institutional investors, who have securities investment funds, pose different influences on stock price volatility in different market environments and structures [5]. They, though the further study on the relationship between investors' structure and stock price fluctuation, find that there is no necessary link between institutional investors and stable stock market. The view of "Institutional investors could stabilize stock market” is partial [6].

Li Yanyi (2012) finds the development courses of open-ended funds can be divided into 4 phases. The theoretical and empirical analysis on the influence of open-ended funds on stock market volatility shows that stock market volatility is aggravated after open-ended funds enter into stock market. She further has the micro-level analysis of the effects of internal elements of open-end fund on stock market volatility, and concludes that the volatility of the stock market has a positive correlation with fund flow rate of open-ended market, shareholding proportion, ownership concentration, redemption rates and environmental factors and other explanatory variables [7].

Although scholars have not reached the same conclusion on the main impact of institutional investors on the stability of stock market, but most scholars hold “Open-end fund exacerbates stock market volatility”. One reason may be a data problem. For example, some documents don’t conduct researches on all samples of a particular fund, leading to big differences in conclusions. At present, research in this area has been gradually transited from theory to empirical research. With the development of econometric models, there will be more and more studies like this, the results will be more accurate.

According to the above analysis, this article captures asymmetric effects that the positive and negative impact brings to stock market volatility by constructing GARCH-M and EGARCH-M model, and conducts research on the open fund market of China.

\section{The Development of Open-End Fund in China}

In September 2001, the first open-ended securities investment fund-Hua an innovative securities investment 
fund was established, which marks China's securities investment fund industry entered into a new stage of development. At the end of 2002, open-ended funds increased from 3 in 2001 to 17. After the initial success of pilot phase of open-ended funds, the funds started to expand rapidly. Figure 1 shows the comparison of the open funds and closed-end funds in terms of its net assets, showing that open-end funds exceed closed-end funds in scale.

Through the contrast of the diagram above, you can see that the current development of open-ended fund in China has the following characteristics:

The first, smaller scale, faster growth rate Compared with the world's major developed countries, the development of China's securities market is not mature enough, and the open-ended fund was launched too late. It is still at an early stage. Compared with the United States and other developed countries, fund industry in China is very small in size for the quantity of funds and the net assets. But, in the context of policy support and rapid socio-economic development of the country, open-ended funds in China is still in a stage of rapid development. Figure 1 shows that since the first open-ended fund was launched in 2001 in China, the number of open-ended funds enjoys a linear increase, then increases in a stable manner. By the end of February, the number of openended funds in our country reached 1145, with 2.913797 trillion fund units and 2.740115 trillion of net assets. However, the number of closed-ended funds in our country reached 70, with 146.72 billion fund units and 150.323 billion of net assets. Open-ended funds take up $95.22 \%$ of all funds, and the total asset nets account for $94.80 \%$ of total fund nets. So that, we can see open-ended fund has gradually become a major force of security\& fund industry in China.

Secondly, scale of fund shows a slight decrease after its explosive growth [8]. Figure 2 shows the net asset value of open-ended funds experiences explosive growth before 2008. However, in the following 4 years, the net

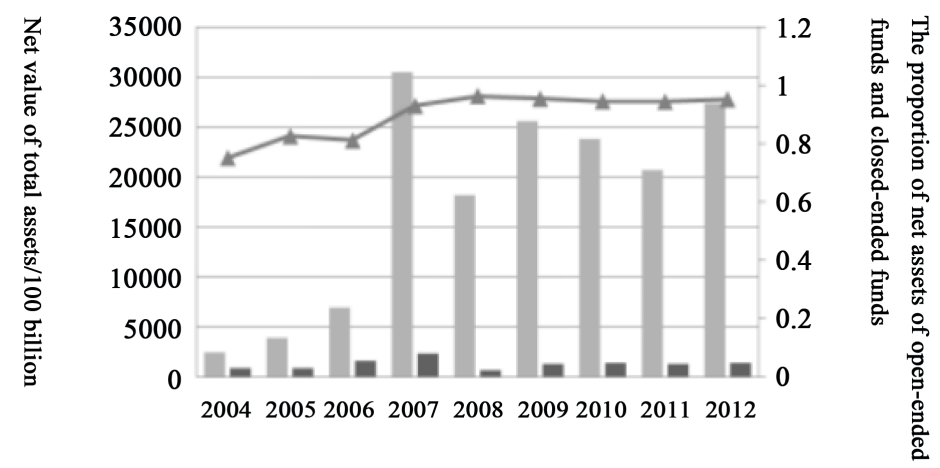

Open-ended fund $\_$Close-ended fund $\_$The proportion of open-ended funds

Figure 1. Comparison on net assets of open-ended funds and closed-ended funds in China (2004-2012).

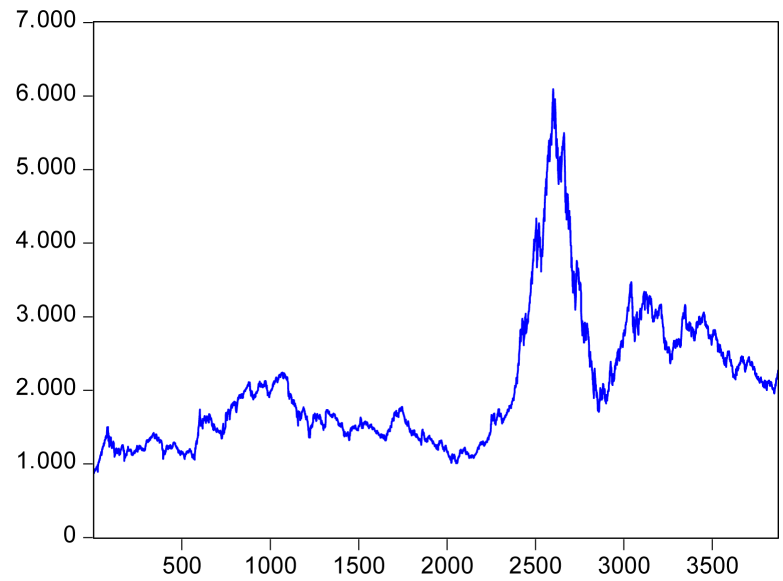

Figure 2. The Shanghai composite index trend from January 2, 1997 to December 31, 2012. 
asset of value shows a trend of decline. Although, it picked up again in 2012, the decline trend still called attention of relevant authorities. Figure 3 shows that the whole development status of total asset is relatively stable, but it still keeps the big scale with more than 2 trillion fund units. Factors causing such a situation include external factors, as well as internal factors. On one hand, the structure of investment subjects is not reasonable, which can be seen in the long-term dominance status of individual investors in security market, and the proportion of institutional investors is low. Compared with individual investors, institutional investors enjoy a long shareholding time and large shareholding quantity so that they play an important role in stabilizing market. Strong fluctuation of market quotation is always accompanied with impact caused by large purchase and redemption, which greatly hinders the development of open-ended funds. Therefore, a stable market is very important for the long-term development of open-ended fund. On the other hand, the development of open-ended fund in China is not such long, and it lacks of sufficient development experiences and established laws and regulations. In addition, the lack of fund managers with high quality and strong management capacity hinders the development of open-ended funds to some degree. Currently, China is lack of fund management experts with rich theoretical knowledge and practical experience so that there are still some improper investments. Drawbacks still exist in the governance of fund management companies, which cannot provide effective investment consulting service, and properly direct the rational investment of investors. This does harm to the stability of stock market to some degree.

\section{Methodology}

Academic research on financial filed in early period supposes that the fluctuation of security profits is unchanged. However, further study shows stock market could have the sudden fluctuations. Another big fluctuation occurs after one big fluctuation and another small fluctuation occurs after one small fluctuation. That means variances always have the time-varying characteristics and clustering characteristics. Hereafter, foreign scholars conducted a lot of researches on the fluctuations of price of financial assets, finding that conditional heteroscedasticity exists in financial asset returns. Engle (1982), the winner of Nobel Economics Prize in 2003 put forward the autoregressive conditional heteroscedasticity model (ARCH), which can analyze financial time series. Based on this point, Bollerslev (1986) brought forward generalized autoregressive conditional heteroscedasticity model(GARCH). Engle et al. (1987) considered the investment risks of financial assets into the mean equation of GARCH model. GARCH model was extended into GARCH-M model. Nelson (1991) put forward an asymmetrical model, EGARCH model [9].

\subsection{GARCH-M Model}

In most of documentations, GARCH $(1,1)$ is always used to analyze the volatility clustering of financial time series. GARCH $(1,1)$ is a kind of GARCH model, which is often used when stock market volatility is estimated. However, GARCH model supposes that the conditional mean of financial series remains unchanged. However, in most cases, stock returns have an intimate connection with investment risks, so that conditional mean doesn't remain unchanged. GARCH-M model considers this factor into the mean equation of GARCH. The following forms can be set by GARCH $(1,1)$ model:

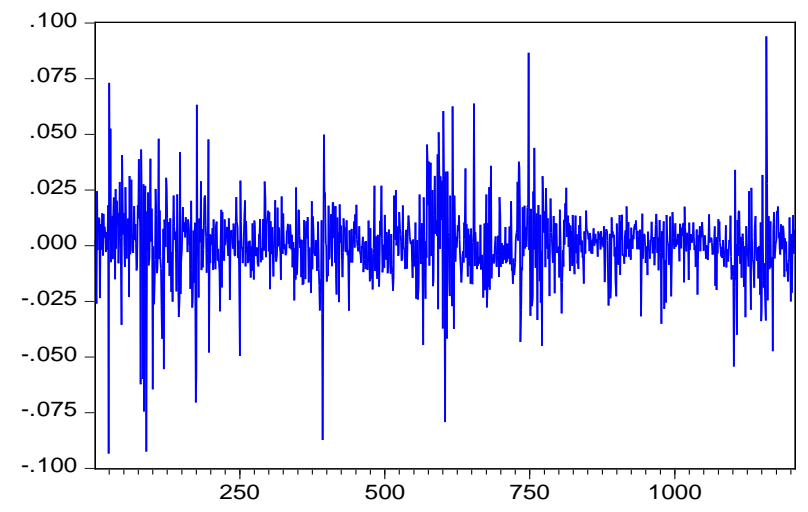

Figure 3. Yield rate of full sample A in Shanghai composite index. 


$$
\begin{gathered}
y_{t}=x_{t}^{\prime} \phi+\gamma \sigma_{t}^{2}+\mu_{t}, \mu_{t} \sim N\left(0, \sigma_{t}^{2}\right) \\
\sigma_{t}^{2}=\alpha_{0}+\alpha_{1} \mu_{t-1}^{2}+\beta_{1} \sigma_{t-1}^{2}
\end{gathered}
$$

Of which, Equation (1) is the mean equation, Equation (2) is the variance equation. It is the logarithm daily yield, is the residual, and is the conditional variance of $t$ period, it is not only related to a residual error in the previous period, as well as to the conditional variance. Conditional distribution hypothesis of disturbing term include normal distribution, $t$ distribution, and generalized error distribution (GED). Here, we assume that the random disturbance term submits to the normal distribution. Mean value introduces a variable in the equation, used to measure the degree of investment risk. In addition to variance, standard deviation, natural logarithm of variance can be used to measure the risk.

Coefficients could measure the relationship between the return rate of financial assets and investment risk. If it is positive value, the higher the investment risk is, the higher the rate of return on financial assets will be; if it is negative value, the higher the investment risk is, the lower the rate of return on financial assets will be. If we measure the impact of new information on the effect of current volatility, smaller value mean new and better quality of speed of information dissemination. It depicts impact of old information on stock market volatility, the higher the value is, the stronger the persistence of volatility shock is, the worse the quality and speed of information dissemination will be [10].

ARCH-GARCH sequence of coefficients is used to depict the persistence of financial volatility, reflecting the impact of external shocks on the persistence of stock price volatility. During the process of model estimation, the smoothness requirement is less than 1. It means that the impact of external shocks on conditional variance will decay exponentially, the conditional variance after shocks will gradually return to its mean value. The smaller the sum of the two is, the faster model restrains itself, the weaker the persistence of fluctuation is. If it is, that means the impact will have a lasting impact.

\subsection{EGARCH-M Model}

EGARCH model, based on GARCH Model, introduces a leverage effect to illustrate asymmetry of information on the fluctuations of the stock market. EGARCH-M model introduces factors of stochastic term into mean equation, and its form of expression is the EGARCH (1,1)-m model of variance:

$$
\begin{gathered}
y_{t}=x_{t}^{\prime} \phi+\gamma \sigma_{t}^{2}+\mu_{t}, \mu_{t} \sim N\left(0, \sigma_{t}^{2}\right) \\
\operatorname{In}\left(\sigma_{t}^{2}\right)=\alpha_{0}+\theta \frac{\mu_{t-1}}{\sigma_{t-1}}+\alpha_{1} \frac{\left|\mu_{t-1}\right|}{\sigma_{t-1}}+\beta_{1} \operatorname{In} \sigma_{t-1}^{2}
\end{gathered}
$$

Of which, Equation (3) is the mean equation, Equation (4) is the variance equation. It is the lever coefficient, and the term determines whether a conditional variance has asymmetric reactions. If variance response is symmetrical, which means volatility of yield does have same reaction no matter the news is good or bad. When the bad news appears (external shocks), we expect to see increase of the yield volatility. That means, the impact of bad news poses a bigger impact to stock price volatility than that of good news. When the good news appears (external shocks), we expect to see decrease of yield volatility. That means the impact of good news poses a bigger impact to stock price volatility that that of bad news [11].

\section{Empirical Analysis on the Impact of Open-Ended Fund on Stock Market Volatility}

\subsection{Sample Selection and Data Processing}

Shanghai composite index represents the all stock indexes on the Shanghai Stock Exchange. It is comprehensive, and enjoys high accuracy. Meanwhile Shanghai stock market enjoys a big transaction volume. Its market value is far bigger than Shenzhen's. Therefore, it is a better representative of China's macroeconomic condition. This article selects the daily closing quotation of Shanghai composite index as the basis for empirical research data. Since 1989, China's stock market has become a pilot. Stock market was sluggish a few years ago, the fluctuation range of stock yield is small. Then, affected by bad news such as the stopping of stock market pilot, and the closing of stock market, the frequency and range of fluctuations are very large. Affected by "3.27 T- bonds fu- 
tures event” in 1995, Chinese stock market became the object of State support. Since 1996, Chinese stock market has implemented the system of limiting the rise and fall of stock market. Then the really good news came to us, Chinese stock market entered into a period of great development. Considering the sharp rise and sharp fall of Chinese stock market before 1996 will pose an impact on our analysis on weather open-ended fund would aggravate fluctuation of stock market. So we select a total of 3872 data from January 2, 1997 to December 31, 2012. Data comes from the Great Wisdom Software. And, we can adopt EViews 7 statistical software for data processing and data analysis. Shanghai composite index during sampling has the trend as shown in Figure 4.

According to the operating time when open-ended funds enter into the stock market time, we can divide the period into two periods:

Open-ended fund doesn't run into the stock market during the first period. We select sample data a total of 1207 data from January 2, 1997 to December 31, 2001. According to the stock market, we select two typical stages from this period for the research:

Phase 1: A total of 492 data from May 12, 1997 to May 18, 1999. Big adjustment in this phase is led by excessive speculation. After the blue-chip stocks have been full of speculation, stock index has dropped to 1047 . We can call it a bear market.

Phase 2: A total of 498 data from May 19, 1999, to June 14, 2001. Strong eruptions of network concept stock at this phase would push up the index to 2245 points, the all-time high points so that we can call it a bull market.

Open-ended fund runs into the stock market during the second period. We select a total of 2665 sample data from January 4, 2002, to December 31, 2012. Meanwhile, from this period, we can select two typical stages for research:

Phase 1: A total of 576 data from June 06, 2005 to October 16, 2007. Shanghai composite index in this phase rises from 998 to 6,124 points, which lasts two years and four months, rises 5 times. We can call it a bull market.

Phase 2: A total of 252 data from October 17, 2007 to October 28, 2008. Shanghai composite index drops from 6,124 points to 1664 at this stage. This index drops $73 \%$ in just 1 year. We can call it a bear market.

Specific sample data are divided as follows in Table 1.

This article adopts standard deviation of daily return rate of Shanghai composite index to measure the volatility of Chinese stock market. So, firstly we must calculate the daily return rate of stock market according to daily return rate of Shanghai composite index. Since logarithmic return rate has many good statistical properties, which are conducive to statistical modeling of financial asset price behavior, as well as our analysis, and research. Therefore we choose a logarithmic return rate in this article.

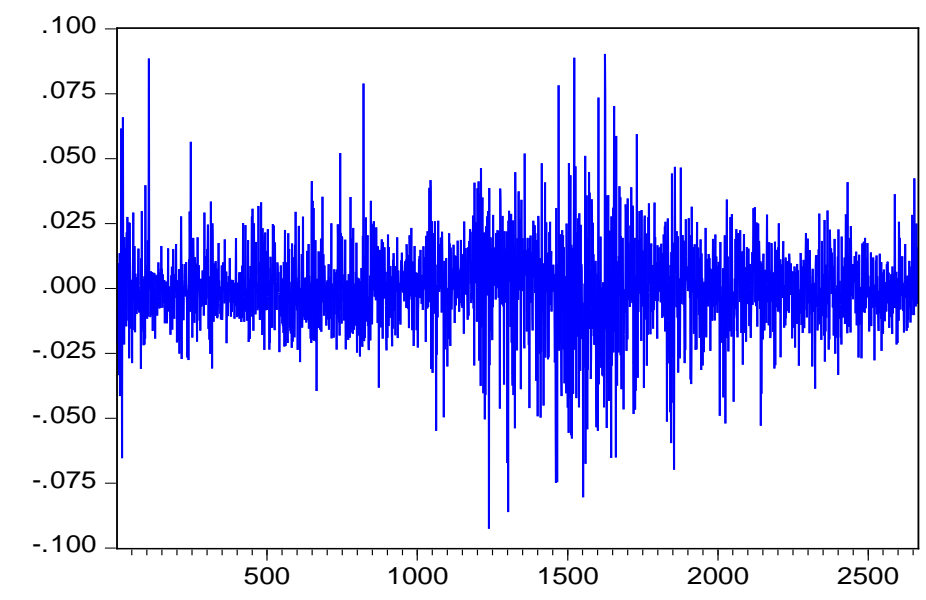

Figure 4. Yield rate of full sample B in Shanghai composite index.

Table 1. Classification of sample data.

\begin{tabular}{ccccccc}
\hline $\begin{array}{c}\text { Time span } \\
\text { of sample }\end{array}$ & $1997.1 .2-$ & $1997.5 .12-$ & $1999.5 .19-$ & $2002.1 .4-$ & $2005.6 .6-$ & $2007.10 .17-$ \\
2001.12 .31 & 1999.5 .18 & 2001.6 .14 & 2012.12 .31 & 2007.10 .16 & 2008.10 .28 \\
\hline \multirow{2}{*}{$\begin{array}{c}\text { Sample Title } \\
\text { Full sample A }\end{array}$} & $\begin{array}{c}\text { Sub-sample A 1 } \\
\text { (Bear) }\end{array}$ & $\begin{array}{c}\text { Sub-sample A } \\
\text { 2 (Bull) }\end{array}$ & Full sample B & $\begin{array}{c}\text { Sub-sample B 1 } \\
\text { (Bull) }\end{array}$ & $\begin{array}{c}\text { Sub-sample B 2 } \\
\text { (Bear) }\end{array}$ \\
\hline
\end{tabular}


The yield rate trend of full sample A and B is shown in Figure 5 and Figure 6. Two figures show that daily yield rate of Shanghai composite index during sample period fluctuates around zero. A small fluctuation follows a small fluctuation, and a big fluctuation follows a big fluctuation, showing the clustering phenomenon of yield rate of stock and other high-frequency data. According intuitive judgments of this figure, after open-ended funds run into the stock market, frequency and degree of stock fluctuation are not reduced.

\subsection{Analysis of Basic Statistic}

Histogram about yield rate of full sample A and B, and some basic statistics are shown in Figure 5 and Figure 6. From these basic statistics, skewness of daily yield rate of two samples are respectively -0.342841 and -0.149363 , indicating that the distributions of daily yield rates of full sample A and B are left-skewed distributions. The kurtosis of daily yield rate of two samples are respectively 8.956782 and 6.644817, which are bigger than the kurtosis in normal distribution, indicating that yield rate series present a leptokurtosis and fat tail distribution characteristics. Jarque-Bera statistics also rejects supposition that two daily yield rate series of Shanghai composite index during the two samples have normal distribution. According to the relevant literature, similar research on stock market in US shows that the general skewness coefficient is -0.3 , and general kurtosis coefficient is 3.8. Compared with this, kurtosis coefficient in Chinese stock market is obviously larger, indicating that Chinese stock market has a strong speculation [12].

In addition, the standard deviation of daily yield rate of Shanghai composite changes from 0.016479 to 0.016756 , its maximum changes from 0.04014 to 0.090348 . The minimum goes from -0.093354 to -0.092582 , indicating the volatility of the full sample B is bigger, but the full sample A is more stable. The above compare-

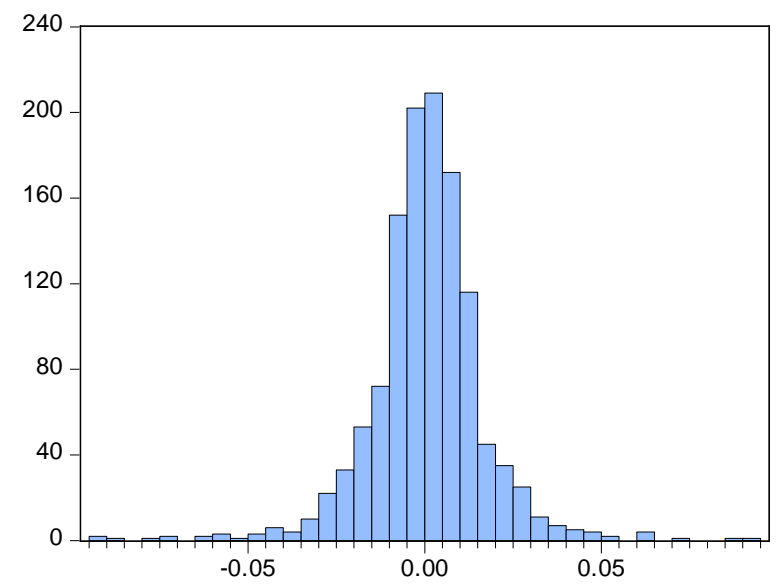

\begin{tabular}{|lr|}
\hline \multicolumn{2}{|l|}{ Series: SAMPLEA } \\
Sample 1 1207 \\
Observations 1207 \\
Mean & 0.000485 \\
Median & 0.000789 \\
Maximum & 0.094014 \\
Minimum & -0.093354 \\
Std. Dev. & 0.016479 \\
Skewness & -0.342841 \\
Kurtosis & 8.956782 \\
& \\
Jarque-Bera & 1808.157 \\
Probability & 0.000000 \\
\hline
\end{tabular}

Figure 5. The histogram and basic statistics of full sample A of Shanghai composite index.

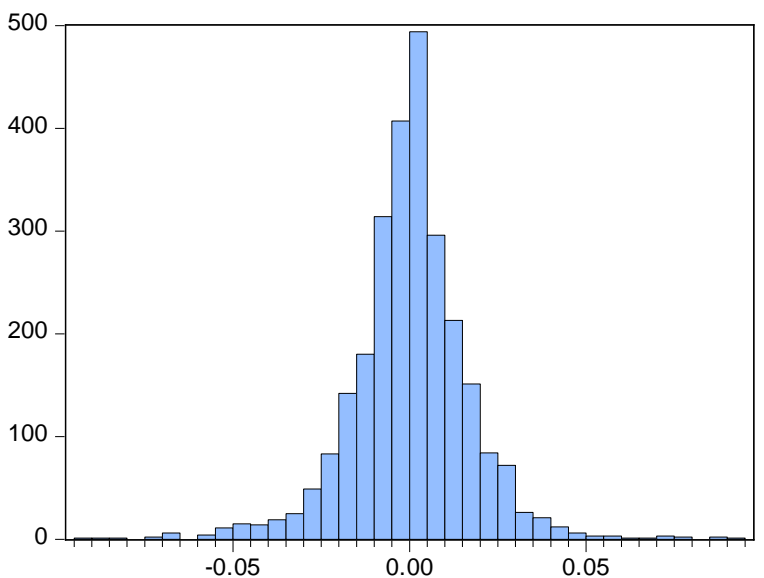

Series: SAMPLEB

Sample 12665

Observations 2665

Mean

Median

0.000120

Maximum

0.000499

0.090348

$\begin{array}{lr}0.092562 \\ \text { Std. Dev. } & 0.016756\end{array}$

Skewness $\quad-0.149363$

Kurtosis $\quad 6.644817$

Jarque-Bera $\quad 1485.064$

Probability $\quad 0.000000$

Figure 6. The histogram and basic statistics of full sample B of Shanghai composite index. 
son preliminarily indicates that since open-ended funds enter into the Chinese stock market, the volatility of Chinese stock market has not been weakened. On the contrary, this trend has been intensified. According to the statistical characteristics of index of daily yield rate, we can analyze the fluctuation of high-frequency financial data by using ARCH-class models.

\subsection{Stationary Test of Sample Data}

In most of the time, series models are based on smooth sequence. Therefore when conducting time series analysis, researchers must use sample data to have stationary test, otherwise it may lead to the problem of spurious regression. If this problem exists, the regression equation would be meaningless, which may lead to terrors in analysis and conclusions. In this article, the daily yield rate series of Shanghai composite adopts ADF unit root test. As it can be seen from Figure 6, significant deterministic trend doesn't exist in yield rate data, so we chose the ADF test mode with intercept terms but without trend items:

$$
\Delta p_{t}=c+\rho p_{t-1}+\sum_{i=1}^{m} \phi_{i} \Delta p_{t-i}+\varepsilon_{t}
$$

Of which it is the variance of the white noise process, the coefficient of each variable, the null hypothesis and the alternative hypothesis: Since AIC is suitable for small sample and SIC has the characteristics of large sample, so that SIC is selected as a information criterion which can determine the number of optimal lag periods. Test results are shown in Table 2.

The test results in Table 2 shows that when the significance level is $1 \%, 5 \%$, and $10 \%$, t statistics volume is far less than the critical value. We need to reject the null hypothesis or the hypothesis that unit root exists in yield rate sequence. This time series is stationary, so that modeling analysis can be conducted on it.

\subsection{Conditional Heteroscedasticity Examination of Sample Data}

This article adopts ARCH LM method to test weather sample yield rate series have the ARCH effects, or conditional heteroskedasticity. First of all, we can have an analysis on autocorrelation function (ACF) and the partial autocorrelation function (PACF) of daily yield rate series of Shanghai composite index. Then, we can analyze Q-statistics and its associated probability, finding that yield rate of sample has a strong autocorrelation with phase 4 and 15 phase, the autocorrelation coefficients are 0.048 and 0.069 respectively [13]. Mean equation for setting the yield rate of sample:

$$
r_{t}=c+\alpha r_{t-4}+\beta r_{t-15}+u_{t}
$$

Regression result:

$$
\begin{array}{ccc}
r_{t}= & 0.000203+0.046594 \times r_{t-4}+0.068062 \times r_{t-15} \\
(0.757094) & (2.901471) & (4.238790) \\
(0.4490) & (0.0037) & (0.0000)
\end{array}
$$

Of which, the first line under expression equation is t-statistics; the second line is adjoint probability; the con-

\begin{tabular}{|c|c|c|c|c|c|c|c|}
\hline & & \multicolumn{3}{|c|}{ Before the issuing of open-ended funds } & \multicolumn{3}{|c|}{ After the release of the open-ended funds } \\
\hline & & Full sample A & Sub-sample A 1 & Sub-sample A 2 & Full sample B & Sub-sample B 1 & Sub-sample B 2 \\
\hline \multicolumn{2}{|c|}{ t-Statistic } & -35.33842 & -21.83044 & -22.18491 & -51.41401 & -24.29083 & -16.11017 \\
\hline \multirow{3}{*}{$\begin{array}{c}\text { Test } \\
\text { critical } \\
\text { value }\end{array}$} & $1 \%$ level & -3.435559 & -3.443442 & -3.443281 & -3.432612 & -3.441493 & -3.456302 \\
\hline & $5 \%$ level & -2.863728 & -2.867207 & -2.867136 & -2.862425 & -2.866348 & -2.872857 \\
\hline & $10 \%$ level & -2.567985 & -2.569850 & -2.569812 & -2.567286 & -2.569390 & -2.572875 \\
\hline
\end{tabular}
stant term- $t$ statistics is at the low level of $5 \%$. So that it does not have the significance. After having the regression equation, we can directly select the ARCH effect in the Eviews 7 software for testing, and test results are shown in Table 3.

Table 2. Stationary ADF test of data yield rate for each sample index. 
Table 3. Conditional heteroscedasticity test of daily yield rate of Shanghai composite index.

\begin{tabular}{clll}
\hline F-Statistic & 101.1476 & Prob. & 0.0000 \\
Obs * R-squared & 98.61202 & Prob. & 0.0000 \\
\hline
\end{tabular}

According to test results in Table 3, statistical magnitude of full sample A: Obs * R-squared is with adjoint probability of 0.0000 . It rejects the null hypothesis. So that obvious ARCH effects exist in daily yield rate of Shanghai composite index. ARCH family models can be used to study on the volatility of China's stock market.

\subsection{Empirical Results Analysis Based on GARCH-M Mode}

Because ARCH models of higher order can be replaced by a low order of the GARCH model, so that we can use GARCH $(1,1)$ model to describe the volatility of yield rate. In Equation (6), constant term t statistics in the mean equation under significance level of $5 \%$ is not significant, indicating that conditional equation of daily yield rate series of Shanghai composite index is not permanent, and problems exist in the setting of mean equation. We know that in the General case, yield rate of financial assets and investment risks are closely linked, so that this factor needs to be taken into account in the GARCH model in order to convert this model into GARCH- M model.

We can use GARCH-M model to test the series of daily yield rate, GARCH term in the mean equation is established in the form of standard deviation. Conditional distribution hypothesis of random disturbance term is $t$ distribution, results are as shown in Table 4.

Firstly, (sample A and sample B) test results in two periods before and after open-ended funds enter the stock market and run. The table shows that, full sample A is relatively large, relatively small, and close to 1 , which means ARCH effects in the stock market appear apparently before the launching of open-ended fund. Maybe the influence of stock market policy effect leads to this during this period. Major policies have a significant impact on stock market volatility. Full sample B obviously decreases or increases in a larger degree than before its release. It is closer to 1 , indicating that market conditional variance tends to decrease after the introduction of open-ended fund and the effects of external shocks on stock market volatility last longer, and become more continuous.

Secondly, comparison of test results of bull market (sub-sample A2 and B1) and bear market (sub-sample A1 and sub-sample B2) before and after open-ended funds enter the stock market bull market and run. When it is the bull market, the sum of coefficients is larger than that before the release of open-ended fund; when it is the bear market, the sum of coefficients is smaller than that before the release of open-ended fund. This shows that after the introduction of open-ended funds, when it is the bull market, stock market volatility becomes larger than that before the release; when it is the bear market, stock market volatility becomes smaller that that before the release.

In the end, we can compare the test results of bull market and bear market (sub-sample A1 and sub-sample A2) before open-ended funds enter stock market and run and bull market and bear market (sub-sample B1 and sub-sample B2) after open-ended funds enter stock market and run. Results show that both before and after the release of open-ended funds, sum of two coefficients in bull market is larger than that in bear market. This difference is enhanced after the release of open-ended fund. It indicates that impact of information shocks on stock market volatility is asymmetric, and there is a leverage effect.

Through the above analysis, before and after open-ended fund enters stock market and run, the introduction of open-ended fund exacerbates the volatility of the stock market. However, when the stock markets are in different status, open-ended funds show different effects on the stock market. Volatility increases when it is bull market, market volatility decreases when it is bear market. This may be caused by the leveraged effect of stock market volatility.

\subsection{Analysis of Empirical Results Based on EGARCH-M Model}

Due to the leveraged effect of stock market volatility, so that we need to introduce asymmetric GARCH model and EGACH model for analysis again. Take investment risk into average equation, then convert it into EGARCH-M. Model test results are as shown in Table 5. 
Table 4. Test results of GARCH-M model.

\begin{tabular}{ccccccc}
\hline & \multicolumn{3}{c}{ Before the issuing of open-ended funds } & \multicolumn{3}{c}{ After the release of the open-ended funds } \\
\cline { 2 - 7 } & Full sample A & Sub-sample A 1 & Sub-sample A 2 & Full- sample B & Sub-sample B 1 & Sub-sample B 2 \\
\hline$\alpha_{0}$ & $1.27 \mathrm{E}-05$ & $1.90 \mathrm{E}-05$ & $3.70 \mathrm{E}-06$ & $3.49 \mathrm{E}-06$ & $7.28 \mathrm{E}-06$ & 0.000286 \\
$\alpha_{1}$ & 0.190394 & 0.11883 & 0.11273 & 0.063274 & 0.075573 & 0.005894 \\
$\beta_{1}$ & 0.782912 & 0.790761 & 0.850928 & 0.925648 & 0.902347 & 0.641315 \\
$\alpha_{1}+\beta_{1}$ & 0.973306 & 0.909591 & 0.963658 & 0.988922 & 0.97792 & 0.647209 \\
\hline
\end{tabular}

Table 5. Test results of EGARCH-M model.

\begin{tabular}{ccccccc}
\hline & \multicolumn{2}{c}{ Before the launching of open-ended fund } & \multicolumn{3}{c}{ After the introduction of open-ended fund } \\
\cline { 2 - 6 } & Full sample A & Sub-sample A 1 & Sub-sample A 2 & Full -sample B & Sub-sample B 1 & Sub-sample B 2 \\
\hline$\alpha_{0}$ & $-7.90 \mathrm{E}-01$ & $-6.49 \mathrm{E}-01$ & $-5.08 \mathrm{E}-01$ & $-2.29 \mathrm{E}-01$ & $-1.21 \mathrm{E}-01$ & -9.47534 \\
$\alpha_{1}$ & 0.333136 & 0.13064 & 0.304074 & 0.144829 & 0.102853 & 0.022645 \\
$\theta$ & -0.08309 & -0.1191 & -0.02271 & -0.01581 & 0.065952 & -0.00634 \\
$\beta_{1}$ & 0.935879 & 0.936605 & 0.967874 & 0.985395 & 0.993794 & -0.30662 \\
\hline
\end{tabular}

Firstly, (sample A and sample B) test results in two periods before and after open-ended funds enter the stock market and run. Table 5 shows, null hypothesis that is rejected, indicates that leveraged effects exist before and after open-ended funds enter the stock market and run. If leverage coefficients are less than 0 , it indicates that stock price volatility caused by bad news is greater than stock price volatility caused by good news of the same degree. Compared with full Sample A, full sample B is obviously small, indicating that the effects of information about the stock market volatility on stock market volatility of current period are weakened. If it is obviously big, indicating that after open-ended funds enter into the stock market, the impact of external shocks on stock market volatility becomes more continuous and less stable. The absolute value of the coefficient of leverage is relatively smaller, indicating that the release of open-ended weakens the leverage effect of stock market volatility.

Secondly, we can compare test results of bull market (sub-sample A2 and B1) and bear market (sub-sample A1 and sub-sample B2) before and after open-ended funds enter the stock market and run. When it is the bull market, absolute value leverage coefficient of the sub-sample B1 is larger than before the release of open-ended funds (sub-samples A2). Meanwhile, it is bigger than the absolute value of lever coefficient of full sample B, which indicates that impact of good news on has more effects on stock market volatility. The leveraged effect of stock market volatility increases. When it is the bear market, lever coefficient of sub-sample B2 is less than 0, its absolute value is not only less than that of sub-sample A1, but also less than absolute value of lever coefficient of full sample B, which indicates lever effect of stock market is weakened. The impact of bad news on stock market volatility is less than the impact of good news. It makes stock market more stable, and decreases the volatility of stock market.

Through this analysis, we further verify the conclusions of the GARCH-M model: For the full sample, openend funds' entering the stock market exacerbates volatility in the stock market, but it reduces the leverage effect of stock market. When it is the bull market, open-ended market will not weaken the degree of market volatility. On the contrary, it will further deepen the volatility and leverage effects of stock market. When it is the bear market, open-ended funds will reduce both the volatility of the stock market and leverage effect at the same time.

Considering the status quo and existing problems in the development of open ended fund in China, maybe the following two points can explain why open-ended funds aggravate stock market volatility in China.

Firstly, investor of open-ended fund is the principal, and its manager is also an agent, this principal-agent relationship will inevitably produce this asymmetric information. In fund transaction activities, fund managers 
have more access to information than fund investors, and grasp more comprehensive and accurate information than fund investors. This will lead fund managers tend to do something that is not conducive to the interests of investors, such as blindly investing in securities of high risk and high return. Fund managers will get more administrative expenses once they gain profits, and the losses are borne by the fund investors. This irrational behavior will lead to greater market risk, and aggravate volatility in the stock market. Though fund trustees oversee the investment behaviors of fund managers, fund custodians may not perform their duties well because of drawbacks of law.

Secondly, investors' structure of China's securities market is not sound and mature. At present, China's securities market is still in an extensive trend. It can be seen in more individual investors, and less institutional investors; more speculators, less genuine long-term investors; low overall quality of investors. While open-ended fund, as one of the most important institutional investors, has achieved rapid development in recent years, but compared with large group of individual investors, open-ended fund (institutional investor) accounts for a relatively small proportion. When the market is rising, individual investors will have further expectations of market price and keep buying so as to make price of securities deviate from their intrinsic value; when the market is falling, individual investors will rush to sell their securities, causing further fall of securities prices. The investment behaviors of open-ended fund investors will be under the influence of large retail groups to some extent, thus intensifying volatility of the stock market [14].

\section{Conclusions}

Through the empirical analysis of this article, the following conclusions can be reached: there is a significant leverage effect in Chinese stock market, the introduction of open ended fund weakens the leverage effect of the stock market as a whole, and further deepens the stock market's volatility. When the market is in a different situation, open-ended funds show different effects on the stock market. When the market is rising, its volatility is intensified; when the market is falling, its volatility is weakened.

In order to promote faster and better development of open-ended funds in China, this article proposes two suggestions.

Firstly, we need to create a sound risk management system, and strengthen oversight of open-ended funds industry. In order to effectively control the investment risk of managers of open-ended fund, we should establish a sound system of internal control within the fund management company, and strengthen effective control of the internal risk, and constrain investment behaviors of fund manager. So that fund management activities won't damage the interests of the fund investors for their own interests. In addition, government supervision departments should strengthen oversight mechanism of fund custodian on fund managers, create statutory responsibilities of fund custodian, and continue to improve the relevant legal provisions, so that the fund trustee can fulfill their duties to protect the interests of fund investors.

Secondly, we need to improve the professional quality of individual investors, improve laws and regulations associated with institutional investors. Individual investors often lack expertise and experience in investment, and their investment philosophy is not mature enough. Meanwhile they lack rational investment behavior. However, institutional investors have professionals for investment and financing, and they can make up deficiencies of individual investors in these aspects. Therefore, on one hand, we need to guide the behavior of individual investors when the market rises or falls sharply, so that they can have more comprehensive and clear understanding of the market; on the other hand, we should strengthen legislation, and provide a system guarantee for adjustment of investors' structure so as to vigorously promote the sustained and healthy development of institutional investors in China, and reverse the dominance of individual investors.

This article has showed that open-ended funds have asymmetric influences on the stock market vitality in China, however, the mechanism why asymmetric influences occur still waits to be explored by further research, such as from the view of behavioral finance and supported by empirical data.

\section{References}

[1] Warther, V.A. (1998) Has the Rise of Mutoal Funds Increased Market Stability? Brookings-Wharton Papers on Financial Services.

[2] Dennis, P.J. and Striekland, D. (2003) Who Blinks in Volatile Markets Individual Institutions? Journal of Finance, 57, 1923-1949. 
[3] Chang, E.C. and Wang, Y. (2002) A Study of Mutual Fund Flow and Market Return Volatility. Working Paper, University of Hong Kong, Hong Kong.

[4] Chiyachantana, C.N., Jain, P.K., Jiang, C. and Wood, R.A. (2004) International Evidence on Institutional Trading Behavior and Price Impact. Journal of Finance, 59, 869-898. http://dx.doi.org/10.1111/j.1540-6261.2004.00651.x

[5] He, J. and He, J.B. (2006) Relationship between Structure of Investors and Stock Market Volatility-Based on Thinking of the Theory. The Economy of Southern China, No. 2, 80-90.

[6] He, J., He, J.B., Wang, X. and Huo, W.L. (2007) Will Institutional Investors Certainly Be Able to Stabilize the Stock Market?_Empirical Data From China. Management World, No. 8, 35-42.

[7] Li, Y.Y. (2012) Study on the Effect of Open-Ended Fund on China’s Stock Market Volatility. Master's Degree Thesis, Southwest University of Finance, Chengdu.

[8] Ma, J. (2012) Reflection on Development Status of Open-Ended Fund in China. Time Finance, No. 11, $220-221$.

[9] Zhang, C.S. (2012) Financial Econometrics-Analysis Angle of Time Series. Press of Renmin University of China, Beijing.

[10] Guo, R. (2010) Study on Stability of Our Stock Market and the Open-Ended Funds. Master's Degree Thesis, Northeast University of Finance, Dalian.

[11] Xu, D. (2008) Study on Market Volatility of Open Ended Funds in China Based on GARCH Model. Master's Thesis, North China Electric Power University, Beijing.

[12] Zhao, S.L. and Zhang, N.F. (2011) Empirical Study ARCH Effects of Shanghai Stock Index in China. Sci-Tech Pioneering Monthly, No. 7, 37-38.

[13] Zheng, H. (2008) Study on Influence of Open-Ended Funds on China’s Stock Market Volatility: Master's Thesis, Zhejiang Gongshang University, Hangzhou.

[14] Xu, J. (2008) Analysis on Influence of Open-Ended Fund on Stock Market Volatility/ Master’s Thesis, Yunnan University of Finance, Kunming. 